\title{
CITRA MASYARAKAT DALAM NARATIF LISAN: SATU PENDEKATAN TEORI PENGKAEDAHAN MELAYU
}

\author{
NUR SAMSIAH MAZLAN*, MOHD FIRDAUS CHE YAACOB DAN NASIRIN ABDILLAH
}

Jabatan Pengajian Warisan, Fakulti Teknologi Kreatif dan Warisan, Universiti Malaysia Kelantan, Kampus Bachok, Beg Berkunci No1, 16300, Kelantan.

*Corresponding author: nsamsiah95@gmail.com

Submitted final draft: 28 January 2021

Accepted: 24 February 2021

http://doi.org/10.46754/jbsd.2021.09.007

\begin{abstract}
Abstrak: Naratif lisan merupakan karya yang menjadi milik masyarakat, disebarkan dari mulut ke mulut, dan diperturunkan dari satu generasi ke satu generasi yang lain. Naratif lisan turut kaya dengan citra masyarakat dalam kehidupan dan kebudayaan masyarakat Melayu. Pengkaji menjalankan kajian ini kerana rata-rata masyarakat pada hari ini menganggap naratif lisan sekadar rekaan semata-mata dan tidak menitikberatkan nilai-nilai moral yang mampu membentuk sahsiah diri dalam kalangan masyarakat. Sehubungan dengan itu, kajian ini dilakukan untuk mengenal pasti dan menganalisis citra masyarakat Melayu yang terkandung dalam naratif lisan. Di samping itu, teks Koleksi 366 Cerita Rakyat Malaysia dijadikan bahan utama kajian. Selain itu, pendekatan kualitatif melibatkan kaedah kepustakaan dan teks dijadikan sebagai kerangka panduan untuk menyempurnakan kajian ini. Malah, Teori Pengkaedahan Melayu (1989) oleh Hashim Awang dijadikan deduktif untuk memantapkan analisis kajian. Sebagai kesimpulannya, hasil dapatan kajian membuktikan bahawa naratif lisan sememangnya sarat dengan citra masyarakat yang dapat membentuk adat, nilai dan kebudayaan yang bertamadun dalam kalangan masyarakat Melayu.
\end{abstract}

Kata kunci: Citra masyarakat, naratif lisan, orang Melayu, Teori Pengkaedahan Melayu.

\section{COMMUNITY'S IMAGE IN ORAL NARRATIVE: AN APPROACH ON MALAY THEORY METHDOLOGY}

\begin{abstract}
Oral narrative is a creation that belongs to the community, spread from mouth, and passed down from one generation to another. Oral narrative also rich in imagery and cultural life of the people in the community. Researchers conducted this study because the average society today considers oral narratives as mere fabrications and does not emphasize moral values that are able to shape the personality in society. Accordingly, this study was conducted to identify and analyze the community's image contained in the oral narrative. In addition, the text of Collection 366 Malaysian Folklore is the main material of the study. In addition, a qualitative approach involving library and text methods was used as a guideline framework to complete this study. In fact, the Malay Methodology Theory (1989) by Hashim Awang made to strengthen the deductive analysis of the study. In conclusion, the findings prove that oral narrative is laden with the image of a society that can form the customs, values and culture of a civilized among the Malay community.
\end{abstract}

Keywords: Public image, oral narrative, Malays, Malay Theory Methodology. 


\section{Pengenalan}

Naratif lisan sememangnya sangat sinonim dengan kehidupan masyarakat Melayu. Pada umumnya, kesusasteraan telah lama wujud dalam masyarakat Melayu melalui dua bentuk iaitu dalam bentuk tulisan dan bentuk lisan. Selain itu, kesusasteraan bukan sahaja mempunyai hubungan yang erat dengan penulisnya, namun kesusasteraan juga mempunyai kaitan dengan citra masyarakat dalam masyarakat Melayu. Menurut Harun Mat Piah (2006) sastera sebagai satu seni yang menggunakan kata-kata sama ada dalam bentuk lisan atau bukan lisan. Utley (1965) menyatakan bahawa naratif lisan adalah bercorak lisan yang dituturkan. Hal ini bermaksud, naratif lisan diceritakan secara lisan dari satu generasi ke satu generasi. Manakala Othman Puteh (1996) pula menyatakan bahawa naratif lisan berasaskan keadaan persekitaran dan budaya pada zaman lampau. Tidak ketinggalan, Fatimah Md. Yassin (1990) turut menyatakan bahawa naratif lisan Melayu dapat diguna pakai oleh masyarakat kini sebagai wahana hiburan, sumber didaktik, medium moral dan mendidik individu dalam kalangan masyarakat serta mempunyai nilai murni yang boleh memberi pengajaran kepada masyarakat, khususnya masyarakat Melayu. Seterusnya, Mohd Firdaus Che Yaacob (2018) menyatakan bahawa terdapat hubungan sastera dengan citra masyarakat yang berfungsi untuk memahami tingkah laku dan kehidupannya sama ada melalui pancaindera dan kematangan berfikiran. Citra masyarakat berperanan memberikan gambaran hidup sesuatu masyarakat yang biasanya didapati menerusi nilai budaya, moral, kemasyarakatan, kekeluargaan, agama dan sebagainya yang ada pada sesebuah masyarakat. Citra masyarakat juga banyak menggambarkan realiti sebenar yang wujud dalam kehidupan masyarakat terutamanya dalam kebudayaan dan kepercayaan masyarakat yang boleh dijadikan pedoman dalam kehidupan. Hal ini dapat diperkuatkan lagi dengan pandangan yang dikemukakan oleh Ismail Hamid (1987) yang menyatakan bahawa citra masyarakat dapat menggambarkan fenomena kehidupan, pandangan dan budaya masyarakat tradisi yang diamalkan dan menjadi rutin dalam kehidupan masyarakat sejak turun-temurun. Sehubungan dengan itu, kenyataan itu menegaskan bahawa naratif lisan memperlihatkan hubungannya dengan realiti kehidupan masyarakat yang sebenar, meliputi keseluruhan gambaran kehidupan masyarakat Melayu. Justeru, kajian ini dijalankan untuk mengenal pasti dan menganalisis citra masyarakat dalam teks Koleksi 366 Cerita Rakyat Malaysia.

\section{Sorotan Kajian Lepas}

Analisis sorotan kajian lepas yang dijalankan oleh Azura Abdullah (2000) dalam kajiannya yang bertajuk Kepentingan Cerita Rakyat kepada Kanak-kanak bertujuan mengenal pasti dan menganalisis budaya Melayu yang terkandung dalam cerita binatang dari perspektif kanak-kanak. Dapatan kajian yang diperoleh mendapati cerita binatang menggunakan watak binatang dan kaya dengan budaya Melayu seperti tolong-menolong, hormat-menghormati, berbudi, berhemah tinggi, bekerjasama dan kesederhanaan. Selain itu, penerapan budaya Melayu yang terkandung dalam cerita binatang dari perspektif kanak-kanak dapat membentuk moral positif terhadap perkembangan sahsiah mereka. Kajian cerita rakyat oleh Muhammad Azrul Deraman (2011) bertajuk Nilai-nilai Kemanusiaan yang Terkandung dalam Cerita Rakyat hasil karya Zakaria Hitam di Pahang pula bertujuan mengenal pasti dan menganalisis nilai-nilai kemanusiaan yang terkandung dalam cerita rakyat hasil karya Zakaria Hitam. Kajian ini mengaplikasikan Teori Sosiologi untuk memantapkan lagi hujah. Kajian ini turut menunjukkan bahawa cerita rakyat kaya dengan nilai-nilai kemanusiaan dan menggambarkan kebudayaan masyarakat Melayu yang dapat mendidik moral masyarakat. Seterusnya, Mohd Firdaus Che Yaacob dan Normaliza Abd Rahim (2016) menerusi kajian mereka yang bertajuk Nilai Baik Hati menerusi Cerita Rakyat Melayu terhadap Masyarakat Melayu Suatu Aplikasi Teori Pengkaedahan Melayu bertujuan mengenal pasti nilai baik hati yang terkandung dalam cerita rakyat Melayu. Selain itu, Teori 
Pengkaedahan Melayu dijadikan deduktif untuk memantapkan analisis kajian. Justeru, dapatan kajian ini telah membuktikan bahawa cerita rakyat sememangnya sarat dengan nilainilai murni yang boleh dijadikan pedoman dan teladan khususnya kepada masyarakat Melayu dan pengaplikasian Teori Pengkaedahan Melayu dilihat dapat memperlihatkan kebaikan dan kebajikan masyarakat Melayu.

Selanjutnya, Mohd Firdaus Che Yaacob dan Normaliza Abd Rahim (2014) turut menjalankan kajian terhadap Cerita Rakyat Membentuk Moral Positif Kanak-kanak melalui Nilai Murni. Kajian ini dilakukan untuk mengenal pasti dan menganalisis nilai murni menerusi cerita rakyat terhadap pembentukan nilai-nilai murni dalam kalangan kanak-kanak. Pengkaji telah menggunakan buku Koleksi Himpunan 366 Cerita Rakyat di Malaysia untuk dijadikan sebagai bahan utama kajian. Hasil dapatan kajian ini telah membuktikan bahawa cerita rakyat Melayu kaya dengan nilai-nilai murni yang dapat membentuk moral positif dalam kalangan kanak-kanak. Seterusnya, kajian cerita rakyat turut diberi perhatian oleh Siti Zubaidah Zakeria dan Nik Rafidah Nik Muhamad Affendi (2014) menerusi kajian yang bertajuk Konflik dalam Cerita Rakyat dan Kesannya kepada Kanak-kanak. Kajian ini bertujuan mengenal pasti dan menganalisis konflik yang berlegar dalam kalangan masyarakat Melayu. Kajian ini menggunakan koleksi cerita rakyat yang terdapat dalam majalah Dewan Pelajar terbitan Dewan Bahasa dan Pustaka yang disiarkan pada setiap bulan. Hasil yang diperoleh daripada kajian ini menunjukkan ketinggian akal budi masyarakat Melayu dahulu dapat dikesan apabila kanakkanak mendapat pengajaran daripada peristiwa lepas.

Seterusnya, Nik Rafidah Nik Muhamad Affendi (2016) menerusi kajian beliau yang berfokuskan kepada Pengurusan Konflik dalam Cerita Rakyat Nusantara Abad Ke19 menggunakan pelbagai pendekatan untuk menyelesaikan pergaduhan, pertelingkahan, masalah dalaman manusia dan sebagainya dapat dikesan dalam cerita-cerita rakyat masyarakat
Melayu. Beberapa cerita rakyat dari perspektif kanak-kanak juga telah dipilih untuk meneliti pengurusan konflik yang terdapat dalam cerita rakyat. Hasil kajian menunjukkan terdapat kaedah tertentu yang digunakan oleh masyarakat Melayu tradisi dalam pengurusan konflik. Selain itu, kajian oleh Mohd Firdaus Che Yaacob dan Nasirin Abdillah (2017) yang berjudul Penerapan Falsafah Pendidikan Kebangsaan melalui Cerita-cerita Rakyat Melayu: Kajian Teks Himpunan 366 Cerita Rakyat Malaysia diselenggarakan oleh Aripin Said dan Othman Puteh bertujuan untuk mengenal pasti dan menganalisis cerminan moral positif masyarakat Melayu yang terkandung dalam cerita-cerita rakyat Melayu dengan menggunakan Teori Pengkaedahan Melayu. Beberapa cerita rakyat yang telah dipilih ialah Awang yang Lurus, Padi Berbuah Emas, Raja Kuyuk dan Seuncang Padian Penjual Api yang Lurus. Dapatan kajian ini membuktikan bahawa elemen nilai murni kejujuran ternyata jelas terkandung dalam ceritacerita rakyat Melayu terpilih dan penemuan nilai murni seperti ini telah membuktikan bahawa sememangnya masyarakat Melayu pada masa lampau mengamalkan nilai murni dalam kehidupan untuk memastikan kehidupan yang sejahtera.

\section{Penyataan Masalah}

Pengkajian terhadap naratif lisan ini dijalankan berdasarkan sorotan literatur yang diperoleh daripada para penulis di Malaysia. Tidak dinafikan bahawa rata-rata para penulis memberi fokus kepada pengkajian terhadap unsur instrinsik dan ekstrinsik dalam naratif lisan. Sehubungan itu, pengkaji-pengkaji yang lepas lebih memfokuskan kajian mengenai aspek nilai dalam naratif lisan. Hal ini dapat dibuktikan melalui beberapa kajian seperti Kepentingan Cerita Rakyat kepada Kanak-kanak oleh Azura Abdullah (2000), Kepentingan Cerita Rakyat Melayu yang BerbentukDongeng kepada Kanakkanak oleh Siti Nor Balkish (2000), Nilai-nilai Kemanusiaan yang Terkandung dalam Cerita Rakyat Hasil Karya Zakaria Hitam di Pahang oleh Azrul Deraman (2011), Cerita Rakyat 
sebagai Medium Pendidikan kepada Kanakkanak oleh Lily Syazwani Razali (2011) dan Nilai-nilai Murni dalam Seuntai Himpunan 366 Cerita Rakyat Malaysia oleh Mohd Firdaus Che Yaacob (2015). Selain itu, kajian seperti Cerita Rakyat Membentuk Moral Positif Kanak-kanak Melalui Nilai-nilai Murni oleh Mohd Firdaus Che Yaacob dan Normaliza Abd Rahim (2014), Nilai Baik Hati menerusi Cerita Rakyat Melayu terhadap Masyarakat Melayu Suatu Aplikasi Teori Pengkaedahan Melayu oleh Mohd Firdaus Che Yaacob dan Normaliza Abd Rahim (2016), Penerapan Falsafah Pendidikan Kebangsaan melalui Cerita Rakyat Melayu: Kajian Teks Himpunan 366 Cerita Rakyat Malaysia oleh Mohd Firdaus Che Yaacob dan Nasirin Abdillah (2017) turut memfokuskan kepada aspek nilai dalam naratif lisan. Sehubungan dengan itu, hasil daripada pengamatan terhadap kajian-kajian lepas, didapati bahawa terdapat kelompongan dari segi citra masyarakat yang terkandung dalam naratif lisan. Aspek ini masih kurang dijalankan dan diberi perhatian khusus oleh pengkaji terdahulu. Oleh hal yang demikian, kajian terhadap citra masyarakat dalam naratif lisan wajar dilakukan untuk mengisi kelompongan kajian terdahulu. Memandangkan naratif lisan sememangnya akrab dengan kebudayaan masyarakat, maka pembuktian secara khusus terhadap citra masyarakat yang terkandung di dalamnya wajar diperjuangkan dalam dunia akademik. Justeru, kajian ini dijalankan untuk mengisi kelompongan yang ada dan membuka minda masyarakat mengenai kepentingan kajian ini dengan mengenal pasti dan menganalisis Koleksi 366 Cerita Rakyat Malaysia.

\section{Batasan Kajian}

Kajian ini menggunakan teks Koleksi 366 Cerita Rakyat Malaysia yang diselenggara oleh Zainariah Abdul Wahab, Nur Syafiqa Yusoff dan Fatimah Abdul Nasir dengan memfokuskan kepada beberapa buah naratif lisan yang terkandung cerita Lebai Malang, Kampung Rembau, Pemilihan Pengganti, Kalimah Bismillah, Burung Qaf Wau, Asal Usul Sungai Pinggan, Kota Kulit Kerang, Burung Rajawali yang Ganas, Orang Kaya Bakhil dan Kasih Sayang Keluarga. Kajian ini menjadikan Teori Pengkaedahan Melayu sebagai deduktif kajian untuk memantapkan analisis dan dapatan kajian. Kajian ini menggunakan reka bentuk kualitatif iaitu kaedah kepustakaan dan teks.

Koleksi 366 Cerita Rakyat Malaysia dicetak pada tahun 2017 dan mengandungi 366 cerita rakyat. Beberapa buah cerita rakyat dipilih secara rawak iaitu Lebai Malang, Kampung Rembau, Pemilihan Pengganti, Kalimah Bismillah, Burung Qaf Wau, Asal Usul Sungai Pinggan, Kota Kulit Kerang, Burung Rajawali yang Ganas, Orang Kaya Bakhil dan Kasih Sayang Keluarga.

Seterusnya, pengkaji telah mengaplikasikan Teori Pengkaedahan Melayu dalam kajian ini. Teori Pengkaedahan Melayu telah digagaskan oleh Hashim Awang pada tahun 1989 dan dikemukakan berlandaskan semua aspek kehidupan manusia yang merangkumi cara dan sikap hidup serta kepercayaan dan kebudayaan setempat dalam masyarakat Melayu yang melahirkan karya sendiri. Sehubungan dengan itu, teori sastera ini memperlihatkan perutusan serta lontaran idea dan fikiran pengarangnya berasaskan prinsip kehidupan masyarakat. Teori Pengkaedahan Melayu dibahagikan kepada dua iaitu pengkaedahan Alamiah dan pengkaedahan Keagamaan.

Pengkaedahan Alamiah merangkumi Pendekatan Gunaan, Pendekatan Moral dan Pendekatan Firasat. Pendekatan Gunaan merupakan suatu kewujudan objek alam yang mengandungi pelbagai manfaat, hikmat, fungsi dan kegunaan manusia atau khalayak. Alam pula digunakan sebagai sumber ilham pengarang yang diterapkan ke dalam sesebuah karya sastera. Sebuah karya sastera dan alam perlu saling berkaitan demi melahirkan karya yang baik dan bermanfaat untuk menyampaikan pemikiran dan falsafah kehidupan masyarakat. Justeru, kenyataan ini menegaskan bahawa perkaitan antara manusia dan alam berperanan dalam penghasilan sesebuah karya yang baik dan menarik (Hashim Awang, 2002). Seterusnya, Pendekatan Moral merupakan 
sastera berupa kejadian dan objek, namun kejadiannya berdasarkan Pendekatan Moral, bukan lagi berbentuk sesuatu kewujudan yang menyamai alat atau tentang peristiwa yang berlaku atau yang telah dilalui oleh manusia, sama ada memberikan kesan positif atau negatif. Pendekatan Moral bersifat pengalaman hidup manusia, iaitu pengalaman yang dilalui manusia dan maklumat yang berkaitan dengan manusia serta dunia termasuk kejiwaan, kepercayaan (agama), kebudayaan, kemasyarakatan, kebangsaan dan persekitaran yang melibatkan kekuatan ilmu pengetahuan dan daya kreativiti (Hashim Awang, 2002). Selain itu, Pendekatan Seni pula memperincikan mengenai sastera adalah suatu kejadian alam semesta yang memberi dan memperkayakan pengalaman hidup. Namun pengalaman hidup ini lebih mengarah kepada pengalaman pencipta karya yang penuh dengan daya kemisterian. Namun begitu, mimpi yang dilakukan itu secara sedar dan didasari kepada matlamat dan wawasan yang khusus. Pendekatan Firasat sering dikaitkan dengan mimpi, iaitu suatu pengalaman hidup masyarakat Melayu yang sering dianggap bermakna kepada kehidupan untuk menentukan pengertian atau pencarian makna mimpi, dikenali sebagai ta'abir, iaitu proses menemukan makna menerusi tafsiran lambang atau alamat tertentu (Hashim Awang, 2002).

Manakala, Pengkaedahan Keagamaan merangkumi Pendekatan Dakwah, Pendekatan Kemasyarakatan dan Pendekatan Seni. Menerusi Pendekatan Dakwah, sastera menekankan aspek-aspek yang menyentuh segala persoalan berkaitan dengan pengutaraan kebesaran dan sifat-sifat keagungan Allah SWT dalam hasil kesusasteraan Islam. Menurut Hashim Awang (2002), sastera juga dilihat sebagai satu wadah untuk mempertingkatkan nilai ketakwaan seseorang insan terhadap Allah SWT. Sehubungan dengan itu, isi kandungan yang kaya dan sarat dengan nilai Islam mampu membuka minda masyarakat untuk terus melakukan kebaikan berlandaskan ajaran agama Islam. Seterusnya, Pendekatan Kemasyarakatan pula adalah bertujuan mencari kesejahteraan hidup bermasyarakat dan pengukuhan keimanan dan ketakwaan yang boleh diungkap dan didapati dalam sastera Melayu yang berfungsi khusus dengan membawa perutusan besar untuk mensejahterakan dan membahagiakan umat manusia yang secara tidak langsung meletakkan pendekatan ini sebagai 'sastera untuk masyarakat dari perspektif Islam' (Hashim Awang, 2002). Di samping itu, Pendekatan Seni bertujuan meneliti nilai-nilai estetika yang ada padanya. Pendekatan ini menilai aspek unsur keindahan dalam karya sastera. Ia menjadikan karya sastera sebagai persoalan pokok. Menurut Hashim Awang (2002:12) keindahan dalam sastera adalah keindaan yang berlandaskan dirinya kepada nilai-nilai estetika Islam dan tidak bertentangan dengan akidah serta ajaran dan fahaman agama Islam. Keindahan dapat dilihat dari aspek bentuk visual dan penggunaan gaya bahasa, manakala keindahan dalaman merujuk kepada aspek falsafah pemikiran dan mesej yang dibawa dalam sesuatu karya (Hashim Awang, 2002).

\section{Analisis dan Dapatan Kajian}

Pada bahagian ini, kajian ini akan mengenal pasti dan menganalisis citra masyarakat seperti masyarakat mengamalkan kepercayaan kepada Tuhan, masyarakat bekerjasama dan masyarakat mengamalkan kasih sayang yang terkandung di dalam teks Koleksi 366 Cerita Rakyat Malaysia.

\section{Masyarakat Mengamalkan Kepercayaan kepada Tuhan}

Citra masyarakat yang diperoleh dalam teks Koleksi 366 Cerita Rakyat Malaysia adalah seperti masyarakat mengamalkan kepercayaan kepada Tuhan. Menurut Kamus Dewan (2015), kepercayaan definisikan sebagai keyakinan atau akuan akan benarnya (adanya, berlaku dan lain-lain) sesuatu. Tuhan pula menurut Kamus Dewan (2015), merujuk kepada Allah yang mencipta alam semesta. Selain itu, kepercayaan kepada Tuhan merujuk kepada keyakinan wujudnya Tuhan sebagai pencipta alam dan mematuhi segala suruhannya berlandaskan pegangan agama masing-masing selaras dengan 
pegangan rukun iman iaitu beriman kepada Allah. Menurut Hashim Awang (2002), dalam menjalani kehidupan, manusia memerlukan kepercayaan beragama atau pegangan untuk mencapai kesempurnaan dalam kehidupan. Justeru, menerusi cerita rakyat terdapat masyarakat yang mempercayai kewujudan Allah dan melaksanakan ajarannya dalam kehidupan seharian mereka. Hal ini dapat dibuktikan melalui petikan di bawah:

\section{Petikan 1}

Pada zaman dahulu, tinggal seorang lebai bersama isterinya di sebuah desa. Lebai adalah seorang yang pandai mengaji dan taat beribadat. Suatu hari, dia mendapat jemputan ke tiga majlis iaitu, majlis pengebumian, majlis khatam al-Quran dan juga majlis Maulud.

(Zainariah Abdul Wahab, Nur Syafiqa Yusoff \& Fatimah Abdul Nasir, 2017).

Melalui petikan di atas, sumber membuktikan bahawa watak Lebai Malang merupakan seorang insan yang berpegang teguh dan percaya akan kewujudan Allah SWT. Gambaran watak Lebai Malang ialah seorang yang warak dan kuat beragama, pandai mengaji dan taat beribadat. Rahmat (1990) menjelaskan bahawa agama adalah keyakinan manusia kepada alam ghaib dan menuntut para pengikutnya mematuhi peraturan yang dilahirkan. Justeru, masyarakat yang mengamalkan kepercayaan kepada Tuhan dan mengakui sifat-sifat serta kekuasaan-Nya atau kepercayaan kepada sesuatu yang dipuja dan dianggap sebagai sesuatu yang amat berkuasa perlu sebati dan dihayati dalam kehidupan masyarakat agar kehidupan lebih tersusun berlandaskan syariat dan pegangan agama Islam.

Selain itu, naratif lisan yang menggambarkan masyarakat mengamalkan kepercayaan kepada Tuhan adalah melalui cerita rakyat Kampung Rembau. Sebagai sebuah masyarakat yang berpegang teguh dengan ajaran agamanya, mereka akan bergantung sepenuhnya kepada Allah SWT. Masyarakat yang berpegang teguh dengan kepercayaan yang diamalkan juga percaya bahawa setiap yang berlaku pasti dengan keizinan Yang Maha Berkuasa. Haron Din (1990) menjelaskan bahawa kepercayaan yang kudus, menyatakan diri pada hubungan dalam bentuk upacara, penyembahan dan permohonan, dan membentuk sikap hidup berdasarkan ajaran tertentu. Hal ini menunjukkan bahawa masyarakat dalam naratif lisan Kampung Rembau merupakan masyarakat yang mempercayai kewujudaan Tuhan iaitu Allah SWT. Hal ini dapat dibuktikan melalui petikan di bawah:

\section{Petikan 2}

Ketika sedang berehat, mereka terpandang sebatang pokok kayu merbau yang tinggi dan kuat. Batin mencadangkan agar mereka menebang pokok itu dan dijadikan sebagai negeri di situ. Mereka pun mula berganding bahu menebang pokok merbau itu. Namun pokok itu tetap kukuh di situ. Akhirnya mereka berdoa memohon pertolongan Yang Maha Berkuasa. Dengan kehendak-Nya, pokok itu tumbang juga. Kemudian, kawasan yang rata itu dibina negeri. Mereka menamakan kampung itu Kampung Merbau Tua. Lama-kelamaan, nama kampung itu bertukar menjadi Kampung Rembau.

(Zainariah Abd Wahab, Nur Syafiqa Yusoff \& Fatimah Abdul Nasir, 2017).

Menerusi petikan di atas, masyarakat Kampung Rembau digambarkan sebagai masyarakat yang percaya akan kewujudan dan kekuasaan Tuhan. Hal ini dapat dilihat melalui sikap sekumpulan pemuda yang berjaya menghadapi pelbagai rintangan dan cabaran semasa pengembaraan mereka. Semasa mengembara, mereka terpandang sebatang pokok merbau yang tinggi dan kuat. Mereka ingin menebang pokok tersebut dan mahu menjadikan tempat tersebut sebagai negeri. Oleh itu, sekumpulan pemuda tersebut cuba menebang pokok merbau tersebut, namun pokok itu tetap kukuh di situ. Setelah berusaha dan berganding bahu menebang pokok merbau tersebut, mereka berdoa untuk memohon pertolongan daripada Yang Maha Berkuasa 
untuk menumbangkan pokok merbau tersebut. Justeru, dengan kehendak-Nya pokok itu tumbang dan akhirnya mereka membina sebuah negeri di situ.

Citra masyarakat mengamalkan kepercayaan kepada Tuhan juga dapat dilihat dalam naratif lisan yang bertajuk Pemilihan Pengganti. Watak Kadim dalam naratif lisan Pemilihan Pengganti dapat menggambarkan masyarakat yang yakin dan percaya akan kewujudan Tuhan. Naratif lisan Pemilihan Pengganti ini jelas memperlihatkaan bahawa watak Kadim merupakan masyarakat yang memegang keyakinan terhadap wujudnya Tuhan sebagai pencipta alam dan mematuhi segala suruhan-Nya selaras dengan Prinsip Rukun Negara yang menjadikan prinsip kepercayaan kepada Tuhan sebagai tunjang kepada keimanan seseorang bangsa Melayu yang beragama Islam. Selain itu, kepercayaan kepada Tuhan merujuk kepada akidah dan iman seseorang individu terhadap kepercayaan dan agama yang dianuti. Kepercayaan juga merupakan asas kepada pembentukan moral seseorang individu dalam sesebuah masyarakat. Masyarakat yang mengamalkan kepercayaan kepada Tuhan ini dapat digambarkan melalui petikan di bawah:

\section{Petikan 3}

Setelah memastikan semua orang tiada, mereka pun memetik buah mempelam itu. Setelah itu mereka menyerahkan mempelam itu kepada tuan guru mereka. Tuan guru mereka pun mengumpulkan kesemua muridnya. Namun, seorang muridnya bernama Kadim tidak kelihatan. Tuan guru dan anak muridnya yang lain menunggu kehadiran Kadim. "Kadim, mana buah mempelam kamu? Kenapa kamu tidak bawa ke sini?" tanya tuan guru. "Saya tidak dapat petik buah mempelam di dusun tuan guru kerana Allah Maha Melihat," kata Kadim. Tuan guru amat berpuas hati dengan Kadim lalu melantiknya sebagai pengganti. Murid-murid yang lain juga bersetuju dengan perlantikan Kadim.

(Zainariah Abd Wahab, Nur Syafiqa Yusoff \& Fatimah Abdul Nasir, 2017).
Berdasarkan petikan di atas, sumber jelas memperlihatkan watak Kadim yang tidak memetik buah mangga tersebut kerana beliau percaya akan kewujudan Tuhan. Menurut Edi Kurniawan (2016), kepercayaan adalah struktur atau binaan asas yang menghubungkan seluruh kehidupan masyarakat Melayu yang beragama yang dapat mengungkapkan dan membentuk sifat atau ciri keperibadian sesebuah masyarakat. Kadim tidak memetik buah mempelam tersebut kerana taat kepada nasihan tuan gurunya supaya bersikap jujur. Hal ini dapat dibuktikan melalui surah Al-Hujurat ayat ke-18 yang bermaksud, 'Sesungguhnya Allah mengetahui apa yang ghaib di langit dan bumi dan Allah Maha Melihat apa yang kamu kerjakan'. Justeru, Kadim percaya akan kewujudan Allah SWT dan meyakini bahawa Allah Maha Melihat apa sahaja yang berlaku.

Seterusnya, masyarakat mengamalkan kepercayaan kepada Tuhan juga dapat digambarkan menerusi naratif lisan yang bertajuk Kalimah Bismillah. Hal ini dapat digambarkan menerusi watak sepasang suami isteri yang hidup dalam keadaan miskin iaitu Jali dan Kenanga. Walaupun mereka hidup dalam keadaan serba kekurangan dan miskin, mereka tidak pernah merungut dan sentiasa percaya dan berpegang teguh dengan agama yang dianuti. Hal ini dapat dilihat melalui watak Kenanga yang suka membaca Bismillah dalam setiap kerja yang dilakukannya. Kenyataan ini dapat dibuktikan menerusi petikan di bawah:

\section{Petikan 4}

Kenanga suka membaca Bismillah dalam setiap kerja yang dilakukannya. Tetapi perbuatannya itu tidak disukai oleh suaminya. Petang itu, sewaktu ingin menanak nasi, Kenanga membaca Bismillah lalu menyelukkan tangannya untuk mencedok beras. Tiba-tiba, dia terpegang sesuatu. Dia pun menjerit. Alangkah terkejutnya Kenanga apabila melihat gelang emas. Rupa-rupanya kalimah Bismillah itulah yang menjadikan ular itu menjadi gelang emas. Mulai sekarang, abang juga akan membaca Bismillah setiap kali memulakan sesuatu kerja.

(Zainariah Abd Wahab, Nur Syafiqa Yusoff \& Fatimah Abdul Nasir, 2017). 
Petikan di atas menggambarkan sebuah masyarakat yang sentiasa mengamalkan penggunaan kalimah Bismillah dalam setiap perkerjaan dalam rutin hariannya. Penerapan nilai-nilai Islam yang dibicarakan dalam naratif lisan sejajar dengan tuntutan agama Islam terhadap setiap hamba-Nya yang beriman dan bertakwa (Jumali Selamat, 2009). Penggunaan kalimah Bismillah merupakan salah satu amalan yang dituntut dalam agama Islam sebelum memulakan atau melakukan sesuatu pekerjaan. Dalam naratif lisan, Kalimah Bismillah ini telah membuktikan bahawa penggunaan atau amalan Bismillah yang dijadikan sebagai rutin hidup Kenanga itu telah mengubah sesuatu keburukan kepada kebaikan. Hal ini dapat dibuktikan dengan kalimah Bismillah dan dengan izin-Nya itulah yang menjadikan ular itu bertukar menjadi gelang emas. Selain itu, citra masyarakat yang mengamalkan dan berpegang teguh kepada Tuhan juga dapat dilihat menerusi naratif lisan yang bertajuk Burung Qaf Wau. Hal ini dapat dilihat menerusi watak seorang guru mengaji yang alim mengajar anak-anak penduduk kampung mengaji al-Quran di rumahnya. Setiap hari rumah guru tersebut dipenuhi dengan budak-budak mengaji dan rumahnya riuh-rendah dengan bunyi suara mereka mengaji. Hasil usaha guru berkenaan juga ramai anak muridnya yang berjaya menamatkan Juz Amma dan al-Quran. Hal ini dapat dibuktikan melalui petikan di bawah:

\section{Petikan 5}

Dahulunya, ada seorang guru mengaji yang pandai dan alim. Kebanyakan penduduk kampung menghantar anak-anak mereka mengaji dengannya. Setiap kali zuhur, rumah guru itu akan dipenuhi dengan budak-budak. Riuh-rendah bunyi suara mereka mengaji. Selepas sekian lama mengaji, ramai budak berjaya menamatkan Juz Amma dan alQuran.

(Zainariah Abd Wahab, Nur Syafiqa Yusoff \& Fatimah Abdul Nasir, 2017).
Menerusi petikan di atas, sumber memperlihatkan sebuah masyarakat yang mengamalkan kepercayaan kepada Tuhan. Sebagaisebuahmasyarakatyangberpegangteguh dengan kepercayaan dan agama yang dianutinya, masyarakat akan melaksanakan segala perintah dalam kepercayaan. Justeru, suasana masyarakat yang sentiasa mempraktikkan amalan membaca al-Quran dalam kehidupan masyarakat jelas menggambarkan masyarakat sentiasa menjadikan al-Quran sebagai amalan dan panduan hidup. Hal ini selari dengan pendapat yang diutarakan oleh (Jumali Selamat, 2009) iaitu Allah akan mengangkat dan meninggikan darjat orang yang soleh dan berilmu serta meletakkannya di tempat yang mulia. Amalan membaca al-Quran yang dijadikan sebagai rutin dalam kehidupan masyarakat sememangnya menepati kehendak Islam seperti yang dinyatakan dalam surah al-Imran ayat 19, yang menjelaskan sesungguhnya Islam adalah agama yang diredai Allah yang berlandaskan al-Quran dan ia menepati prinsip Ad-din yang bermaksud Islam adalah satu corak hidup yang lengkap dan menyeluruh.

Justeru, citra masyarakat yang mengamalkan kepercayaan kepada Tuhan ini selari dengan Teori Pengkaedahan Melayu melalui Pengkaedahan Keagamaan di bawah Pendekatan Dakwah. Menurut Hashim Awang (2002), Pendekatan Keagamaan berfungsi ke arah memperkembangkan keunggulan Islam melalui nilai kemurnian dan keistimewaan Islam yang boleh menimbulkan daya tarikan kepada masyarakat dan penganutnya. Di samping itu juga, pengkaedahan keagamaan sememangnya kaya dengan unsur-unsur keagamaan yang lazimnya diaplikasikan untuk menyampaikan pemikiran dan falsafah kehidupan masyarakat Melayu. Dalam pada itu juga, naratif lisan dilihat sebagai satu wadah untuk mempertingkatkan nilai ketakwaan seseorang insan terhadap Allah SWT. Penerapan nilai-nilai Islam yang terkandung dalam naratif lisan juga sejajar dengan keperluan negara yang bertujuan membentuk personaliti, sahsiah dan memupuk masyarakat dengan nilai budaya murni yang menjadi amalan dalam kehidupan masyarakat 
sejagat (Jumali Selamat, 2009). Sehubungan dengan itu, isi kandungan yang kaya dan sarat dengan nilai Islam mampu membuka minda masyarakat untuk terus melakukan kebaikan berlandaskan ajaran agama Islam.

\section{Masyarakat Bekerjasama}

Menurut Kamus Dewan (2015), kerjasama didefinisikan sebagai kerja yang dibuat secara bersama-sama, tolong-menolong atau gotongroyong. Citra masyarakat dalam naratif lisan menggambarkan situasi kerukunan dan semangat bekerjasama dalam kehidupan masyarakat Melayu tradisi yang menjadi amalan masyarakat Melayu. Gambaran yang sedemikian digambarkan dalam setiap upacara keramaian seperti dalam kalangan penduduk kampung atau dalam kalangan pembesar istana dengan rakyat jelata. Kerjasama dalam kalangan masyarakat sangat dituntut kerana ia dapat mewujudkan suasana kehidupan yang harmoni. Hal ini bersesuaian dengan pendapat Hashim Musa (2008) yang mengatakan bahawa pentingnya sikap kerjasama dalam sesebuah kehidupan masyarakat Melayu khususnya yang beragama Islam dalam mempertahankan maruah negara yang diduduki. Selain itu, semangat kerjasama yang digambarkan dalam naratiflisan merupakan citra masyarakat dan situasi sebenar kehidupan masyarakat Melayu. Setiap anggota masyarakat perlu menyumbang tenaga demi menjayakan setiap perancangan yang melibatkan masyarakat setempat. Keutuhan semangat yang ditunjukkan merupakan satu kebanggaan yang mungkin tidak terdapat dalam masyarakat lain di dunia. Antara contoh petikan yang menggambarkan semangat kerjasama dalam naratif lisan adalah seperti petikan di bawah:

\section{Petikan 6}

Pelbagai rintangan dan cabaran yang dilalui namun mereka berjaya mengatasinya. Akhirnya mereka tiba di sebuah kawasan yang rata. Batin yang merupakan ketua mereka mengajak mereka berehat di situ. Ketika sedang berehat, mereka terpandang sebatang pokok kayu merbau yang tinggi dan kuat. Mereka mula berganding bahu menebang pokok merbau itu. Namun pokok itu tetap kukuh di situ. Akhirnya mereka

berdoa memohon pertolongan Yang Maha Berkuasa. Dengan kehendak-Nya, pokok itu tumbang juga. Kemudian, kawasan yang rata itu dibina negeri.

(Zainariah Abd Wahab, Nur Syafiqa Yusoff \& Fatimah Abdul Nasir, 2017).

Berdasarkan petikan di atas, sumber turut memperlihatkan citra masyarakat yang saling bekerjasama. Citra masyarakat saling bekerjasama telah dipraktikkan dalam kehidupan masyarakat Melayu sejak dahulu lagi. Hal ini dapat dibuktikan menerusi semangat bekerjasama antara pemuda untuk menyelesaikan sesuatu permasalahan. Pemuda-pemuda tersebut telah berganding bahu dan bekerjasama untuk menebang pokok merbau walaupun tidak berhasil untuk menumbangkannya. Namun dengan berkat usaha dan doa pemuda-pemuda tersebut, pokok merbau yang kukuh itu akhirnya tumbang juga.

Selain itu, semangat bekerjasama dalam masyarakat juga dapat dilihat menerusi naratif lisan yang bertajuk Asal Usul Sungai Pinggan. Kerjasama merujuk kepada amalan atau aktiviti yang dilakukan dalam kumpulan yang ramai dengan tujuan meringankan bebanan. Justeru, kerjasama dalam sesebuah masyarakat telah lama wujud dan telah menjadi amalan dalam kehidupan masyarakat Melayu. Hal ini dapat digambarkan melalui petikan dalam naratif lisan Asal Usul Sungai Pinggan seperti di bawah:

\section{Petikan 7}

Terdapat sebuah kampung di tepi sungai yang terletak di daerah Pontian, Johor. Keluarga Pak Itam baru sahaja berpindah di kampung itu. Tok penghulu dan penduduk kampung bergotong-royong membina rumah Pak Itam. Sebagai tanda terima kasih, Pak Itam menjemput seluruh penduduk kampung menghadiri kenduri di rumahnya.

(Zainariah Abd Wahab, Nur Syafiqa Yusoff \& Fatimah Abdul Nasir, 2017). 
Menerusi petikan di atas, naratif lisan Asal Usul Sungai Pinggan menggambarkan citra masyarakat saling bekerjasama. Amalan kerjasama ini dapat dilihat menerusi perwatakan penduduk kampung di Pontian, Johor yang saling membantu antara satu sama lain. Bagi menghormati Pak Itam yang baru berpindah ke kampung itu, Tok Penghulu dan penduduk kampung telah bergotong royong membina rumah Pak Itam. Pak Itam juga telah mengadakan kenduri di rumahnya sebagai tanda terima kasih atas bantuan yang dihulurkan. Bekerjasama melalui bergotong-royong juga merupakan penyertaan atau sikap saling membantu dalam pelaksanaan tugas secara beramai-ramai tanpa mengira soal upah atau ganjaran yang akan diterimanya (Firdaus Che Yaacob, 2015). Justeru, sikap bekerjasama dan bergotong-royong dalam masyarakat amat dititikberatkan agar sesuatu pekerjaan yang berat dapat dilakukan dengan baik tanpa mengira upah malah dilakukan dengan sukarela dan ikhlas. Citra masyarakat dalam naratif lisan bertajuk Kota Kulit Kerang juga menggambarkan citra masyarakat yang saling bekerjasama. Kerjasama ini dapat dilihat melalui watak dan perwatakan pemerintah dan juga rakyat jelata yang saling bekerjasama untuk mempertahankan negara daripada diserang musuh. Antara petikan yang memperlihatkan citra masyarakat yang saling bekerjasama adalah seperti petikan di bawah:

\section{Petikan 8}

Tengku Syah Nobat mendapat satu akal, baginda mengarahkan Datuk Bendahara agar menyuruh rakyat jelata membuat sebuah kota yang diperbuat daripada kerang. Datuk Bendahara sibuk menjalankan tugasnya, dia menyuruh rakyat jelata bekerja di laut agar menangkap kerang sebanyak mana yang mungkin. Rakyat jelata turut digalakkan untuk memakan kerang. Apabila sudah banyak kulit kerang dikumpulkan mereka pun mula membina benteng kulit kerang setinggi seorang lelaki dewasa.

(Zainariah Abd Wahab, Nur Syafiqa Yusoff \& Fatimah Abdul Nasir, 2017).
Berdasarkan petikan di atas, sumber menggambarkan masyarakat saling bekerjasama. Rakyat jelata telah bekerjasama membuat sebuah kota yang diperbuat daripada kerang. Mereka telah membahagi-bahagikan tugas iaitu rakyat jelata bekerja di laut menangkap kerang sebanyak mungkin, manakala Datuk Bendahara menjalankan tugasnya. Seterusnya, mereka membina benteng kulit kerang setinggi seorang lelaki dewasa untuk berlindung daripada musuh. Akhirnya, mereka berjaya mengalahkan musuh dengan adanya benteng kulit kerang tersebut. Menurut Hashim Musa (2008), amalan kerjasama dan bergotong-royong merupakan salah satu nilai sepunya Melayu dan sudah lama diamalkan dalam masyarakat Melayu. Seterusnya, citra masyarakat yang menggambarkan masyarakat yang saling bekerjasama juga dapat dilihat menerusi naratif lisan yang bertajuk Burung Rajawali yang Ganas. Dalam hal ini, penduduk kampung dan Tok Penghulu saling bekerjasama dalam menyelesaikan permasalahan iaitu burung rajawali ganas yang selalu menyerang kampung mereka. Antara petikan yang memperlihatkan citra masyarakat yang saling bekerjasama adalah seperti petikan di bawah:

\section{Petikan 9}

Suatu hari, seorang anak yatim piatu iaitu, Nibong menemui Tok Penghulu lalu berkata, "Tuk, saya cadangkan kita bina sebuah patung burung rajawali betina yang besar dan juga anak panah yang besar dan panjang. Jika burung rajawali itu nampak patung burung rajawali betina itu, sudah tentu ia akan mendekatinya. Pada waktu itulah, kita beramairamai memanah burung rajawali itu dengan anak panah!'. Bernas sungguh cadanganmu itu, Nibong! Baiklah, aku akan kerahkan penduduk pulau membuat patung burung rajawali betina dan anak panah," balas Tok Penghulu.

(Zainariah Abdul Wahab, Nur Syafiqa Yusoff \& Fatimah Abdul Nasir, 2017).

Sebagaimana petikan sebelumnya, petikan di atas juga menggambarkan sebuah masyarakat yang saling bekerjasama iaitu untuk membantu 
Tok Penghulu membunuh burung rajawali ganas yang sentiasa menyerang kampung mereka. Kerjasama yang ditunjukkan oleh penduduk kampung tersebut dapat dilihat daripada kerjasama mereka membuat patung burung rajawali betina dan anak panah untuk membunuh burung rajawali. Penduduk kampung berkenaan beramai-ramai memanah burung rajawali itu sehingga mati. Menurut Jumali Selamat (2001), bekerjasama melalui aktiviti gotong-royong adalah kesediaan untuk bersama membantu dan melaksanakan sesuatu tanggungjawab atau tugas dengan bekerjasama dan saling membantu yang dilakukan secara sukarela.

Justeru, citra masyarakat saling bekerjasama ini dapat dikaitkan dengan Teori Pengkaedahan Melayu di bawah Pendekatan Kemasyarakatan yang bertujuan mencari kesejahteraan hidup bermasyarakat serta pengukuhan keimanan dan ketakwaan yang boleh diungkap dan didapati dalam naratif lisan (Hashim Awang, 2002). Selain itu, Pendekatan Kemasyarakatan merupakan wadah untuk mencari kebaikan dan keadilan dalam masyarakat yang sangat dituntut dalam Islam. Oleh itu, interaksi dan kerjasama dalam sesebuah masyarakat adalah sangat penting kerana ia merupakan salah satu syarat utama hidup bermasyarakat. Dalam hidup bermasyarakat, tugasan perlu dipikul bersama oleh setiap anggotanya. Hal ini juga selari dengan tuntutan dalam Islam yang sentiasa mengingatkan penganutnya supaya sentiasa membantu untuk menjamin kesejahteraan hidup. Rentetan itu, citra masyarakat yang terdapat dalam naratif lisan berupaya memberi manfaat yang lebih luas kepada masyarakat Melayu yang membacanya.

\section{Masyarakat Mengamalkan Kasih Sayang}

Menurut Kamus Dewan (2015), kasih sayang membawa maksud perbuatan atau perlakuan menyayangi, mengasihi, dan bersifat belas kasihan serta menghormati orang lain. Citra masyarakat yang terkandung dalam naratif lisan juga ialah masyarakat yang mengamalkan kasih sayang antara keluarga. Kasih sayang adalah sikap saling menghormati dan mengasihi semua ciptaan Tuhan. Kasih sayang keluarga adalah perasaan cinta, kasih dan sayang yang mendalam dan berkekalan terhadap keluarga. Menurut Norita Arifin (2006), kasih sayang didefinisikan sebagai perasaan halus dan belas kasihan yang timbul dari hati yang ikhlas terhadap orang lain dan berusaha membantu meringankan bebanan yang dihadapinya. Kasih sayang antara keluarga ini dapat dilihat melalui petikan naratif lisan Orang Kaya Bakhil seperti di bawah:

\section{Petikan 10}

Isterinya, Kuntum berkata, "Benar kata nakhoda itu. Buang sahaja semua peti itu ke dalam laut. Jika tidak kita akan karam." Kelana tidak bersetuju. Nakhoda kapal lalu bertanya, "Yang mana Tuan Kelana lebih sayang? Isteri dan anak-anak atau peti wang ini?" Melihat kapal hendak karam, peti-peti wang itu pun dibuang ke dalam laut. Kapal itu akhirnya jadi ringan dan mereka selamat tiba ke negeri yang hendak dituju.

(Zainariah Abd Wahab, Nur Syafiqa Yusoff \& Fatimah Abdul Nasir, 2017).

Petikan di atas memperlihatkan kasih sayang yang ditonjolkan oleh watak orang kaya bakhil terhadap keluarganya. Kasih sayang terhadap keluarga ini dapat dilihat menerusi watak Kelana yang memilih nyawa isteri dan anakanaknya berbanding wang walaupun pada saat yang getir. Sikap manusia yang penyayang dan sayangkan nyawa ialah manusia yang bertindak untuk menyelamatkan nyawa daripada sebarang perbuatan yang boleh menghilangkan nyawa (Hashim Musa, 2008). Justeru, sikap Kelana yang lebih mementingkan keluarganya ini telah dibalas dengan ganjaran yang lebih baik iaitu mereka sekeluarga selamat tiba di negeri yang dituju dan akhirnya hidup bahagia. Sehubungan dengan itu, sikap Kelana yang tidak pentingkan diri wajar dicontohi oleh masyarakat.

Selain itu, kasih sayang dapat dilihat menerusi naratif lisan yang bertajuk Kasih Sayang Keluarga iaitu melalui watak seorang kakak yang penyayang terhadap adiknya walaupun adiknya dilahirkan dalam keadaan 
ganjil. Selepas kelahiran anak lelaki yang ganjil, sepasang suami isteri tersebut amat malu kerana anak lelakinya bertanduk di kepala dan ingin menghanyutkan anaknya di dalam peti besi ke sungai. Namun, dengan sikap penyayang terhadap adiknya itu, dia sanggup mengikut ke mana sahaja peti yang dihanyutkan ke sungai oleh kedua-dua ibu bapanya itu. Hal ini dapat dibuktikan melalui petikan teks di bawah:

\section{Petikan 11}

Si kakak yang amat sayang akan adiknya mengikut ke mana sahaja peti itu dihanyutkan. Suatu hari, telur itu menetas. Si kakak mendengar bunyi anak ayam menciap. Apabila peti itu hanyut di tepi sungai, si kakak lantas mengambil peti itu. Akhirnya, mereka tiba di sebuah kampung pendalaman. Si kakak lantas menceritakan asal usul mereka dan orang kampung mengenali ibu dan bapa mereka. Kata orang kampung, ibu dan bapanya sering memanggil-manggil mereka. Si kakak dan adik bersatu semula dengan ibu bapa mereka. Mereka anak beranak hidup aman dan damai.

(Zainariah Abd Wahab, Nur Syafiqa Yusoff \& Fatimah Abdul Nasir, 2017).

Berdasarkan petikan di atas, sumber memperlihatkan watak seorang kakak yang mengamalkan kasih sayang dalam keluarganya. Kasih sayang yang ditunjukkan oleh seorang kakak terhadap adiknya ini menggambarkan wujudnya sikap penyayang dalam masyarakat Melayu. Menurut Hashim Musa (2008), masyarakat Melayu memiliki kehidupan yang sangat mementingkan ikatan kasih sayang dalam sesebuah kekeluargaan. Hal ini dapat dilihat ekoran sikap seorang kakak yang sanggup mempertahankan dan mengikuti adiknya setelah dihanyutkan oleh ibu bapanya kerana dilahirkan dalam keadaan ganjil. Perwatakan yang ditunjukkan oleh kakaknya ini menggambarkan beliau bersyukur dan tidak memperlekehkan kurniaan Allah SWT terhadap keluarganya. Rentetan itu, sikap penyayang yang ditunjukkan oleh kakaknya itu menunjukkan sikap positif yang perlu wujud dan ditanam dalam diri setiap anggota keluarga. Dalam pada itu juga, sikap penyayang ini merupakan antara salah satu nilai moral yang perlu dititikberatkan dalam sesebuah keluarga agar tidak berlaku diskriminasi dalam sesebuah keluarga.

Hal ini bertepatan dengan Teori Pengkaedahan Melayu di bawah Pendekatan Kemasyarakatan yang menjelaskan bahawa karya sastera sebagai pembentukan akhlak masyarakat (Hashim Awang, 2002). Citra masyarakat yang mengamalkan kasih sayang turut diutarakan dalam naratif lisan sebagai nilai yang baik dan menjadi ikutan dalam kehidupan. Pembentukan akhlak adalah amat penting dalam memperkasakan modal insan. Dalam hal ini, akhlak yang mulia dapat menjamin masa depan yang cemerlang. Melalui akhlak yang terpuji juga, masyarakat akan sentiasa bermuhasabah diri dan sentiasa berusaha memperbaiki diri ke arah kebaikan.

\section{Penutup}

Secara kesimpulannya, naratif lisan merupakan realiti kehidupan sebenar masyarakat yang mencakupi kehidupan, kebudayaan serta keagamaan. Dalam pada itu juga, citra masyarakat yang terkandung dalam naratif lisan memperlihatkan masyarakat terdahulu mengamalkan sosial budaya yang dipraktikkan sehingga ke hari ini dalam kehidupan dan kebudayaan mereka. Selain itu, citra masyarakat dan nilai-nilai yang terkandung dalam naratif lisan boleh dijadikan teladan kepada masyarakat. Seterusnya, pengaplikasian Teori Pengkaedahan Melayu melalui pendekatan-pendekatannya juga secara tidak langsung membuktikan ketepatan pengaplikasian terhadap naratif lisan yang sesuai dengan kehidupan masyarakat Melayu. Akhir sekali, melalui kajian ini diharap agar dapat membantu pengkaji menghasilkan satu kajian ilmiah yang baik dapat memberi manfaat kepada masyarakat. 


\section{Penghargaan}

Saya ingin merakamkan jutaan terima kasih dan penghargaan buat penyelia saya, Dr. Mohd Firdaus Che Yaacob atas kerjasama teguran dan nasihat secara ikhlas serta sokongan moral sepanjang saya menyelesaikan artikel ini. Tidak lupa juga ucapan terima kasih saya kepada pihak kakitangan Perpustakaan Universiti Malaysia Kelantan, Universiti Putra Malaysia, Universiti Kebangsaan Malaysia, Universiti Malaya dan Dewan Bahasa dan Pustaka yang telah banyak memberikan kerjasama dan menyalurkan bahanbahan kajian bagi menyiapkan artikel ini.

\section{Rujukan}

Azura Abdullah. (2000). Sastera kanak-kanak: meninjau aspek budaya Melayu dalam Cerita Rakyat Binatang dan kesan kepada kanak-kanak. (Tesis Sarjana Sastera). Fakulti Bahasa Moden dan Kominikasi, Universiti Putra Malaysia, Selangor.

Fatimah Yassin. (1990). Cerita Rakyat Sebagai alat pendidikan. Satu analisis isi yang

bercorak etika. Dialog Kesusasteraan (Umar Junus, Rahmah Bujang, Hashim Awang, Mohd. Yusoff Hassan, Wahab Ali, Rahmah Kaeh, Fatimah Yassin \& Zahir Ahmad, Ed). Jabatan Pengajian Melayu, Universiti Malaya, Kuala Lumpur, 11-12 Mei.

Hashim Awang. (2002). Teori Pengkaedahan Melayu dan Prinsip Penerapannya. Seminar Bengkel Kajian Teori Sastera Melayu. Rivera Bay Resort, 20-23 Jun.

Hashim Musa. (2008). Hati Budi Melayu: Pengukuhan menghadapi cabaran abad ke-21. Serdang: Penerbit Universiti Putra Malaysia. Selangor.

Ismail Hamid. (1987). Perkembangan Kesusasteraan Melayu Lama. Petaling Jaya: Longman.

Jumali Selamat. (2001). Nilai-nilai dalam Pantun Melayu. (Tesis Ijazah Sarjana Muda), Fakulti Bahasa Moden dan Komunikasi, Universiti Putra Malaysia, Selangor.
Jumali Selamat. (2009). Aplikasi Teori Pengkaedahan Melayu dalam Menjaras Ribut menerusi pendekatan dakwah. Jurnal Personalia Pelajar Bil.12/Jun. Selangor: Universiti Kebangsaan Malaysia.

Kamus Dewan. (2015). Kuala Lumpur: Dewan Bahasa dan Pustaka.

Lily Salwani Razali. (2011). Cerita rakyat sebagai medium pendidikan kepada kanakkanak. (Tesis Ijazah Sarjana), Fakulti Bahasa Moden dan Komunikasi, Universiti Putra Malaysia.

Mohd Firdaus Che Yaacob \& Nasirin Abdillah. (2016). Penerapan nilai murni dalam Cerita Rakyat Melayu suatu aplikasi teori pengkaedahan Melayu: Analisis nilai kasih sayang dan nilai keadilan dalam masyarakat Melayu. International Journal of Creative Future and Heritage (TENIAT). 5(2).

Mohd Firdaus Che Yaacob \& Normaliza Abd Rahim. (2014). Cerita Rakyat membentuk moral positif kanak-kanak melalui nilai murni. Journal of Business and Social Development, 2(2), 74-85.

Mohd Firdaus Che Yaacob \& Normaliza Abd Rahim. (2016). Nilai baik hati menerusi Cerita Rakyat Melayu terhadap masyarakat Melayu suatu aplikasi teori pengkaedahan Melayu. Journal of Business and Social Devolepment, 4(2), 48-57.

Mohd Firdaus Che Yaacob. (2018). Nilai-nilai murni dalam Naratif Lisan di Lembangan

Sungai Pengkalan Datu, Kelantan: Satu penelitian pengkaedahan Melayu. (Tesis Ijazah Sarjana Doktor Falsafah), Fakulti Teknologi Kreatif dan Warisan. Universiti Malaysia Kelantan.

Muhammad Azrul Deraman. (2011). Nilai-nilai kemanusian dalam Cerita Rakyat hasil karya Zakaria Hitam. (Tesis Ijazah Sarjana Muda), Fakulti Teknologi Kreatif dan Warisan, Universiti Malaysia Kelantan. 
Norita Ariffin. (2006). Nilai budi masyarakat Melayu dalam Pantun. (Tesis Sarjana Sastera), Fakulti Bahasa Moden dan Komunikasi, Universiti Putra Malaysia.

Nik Rafidah Nik Muhammad Affendi. (2016). Pengurusan konflik dalam Cerita Rakyat Nusantara abad ke-19. International Journal of the Malay World and Civilisation (Iman), 4(2), 37-43.

Othman Puteh. (1996). Konsep nilai dalam kebudayaan Melayu. Kuala Lumpur: Dewan Bahasa dan Pustaka.
Siti Zubaidah Zakeria, Nik Rafidah Nik Muhammad Affendi. (2014). Konflik dalam Cerita Rakyat dan kesannya kepada kanakkanak. Jurnal Bahasa, Pendidikan dan Sastera Melayu, 5(1), 185-205.

Utley, L. F. (1965). Folk literature: An operation definition. In Dundes, A., Ed. The study of Folklore New Jersey: Prentice-Hall.

Zainariah Abd Wahab, Nur Syafiqa Yusoff \& Fatimah Abdul Nasir. (2017). Koleksi 366 Cerita Rakyat Malaysia. Kuala Lumpur: Edukid Publication Sdn. Bhd. 